\title{
Effect of immunosuppressive therapy on interferon $\gamma$ release assay for latent tuberculosis screening in patients with autoimmune diseases: a systematic review and meta-analysis
}

\author{
Sunny H Wong, ${ }^{1,2}$ Qinyan Gao, ${ }^{1,3}$ Kelvin K F Tsoi, ${ }^{4}$ William K K Wu, ${ }^{5}$ Lai-shan Tam, ${ }^{1}$ \\ Nelson Lee, ${ }^{1}$ Francis K L Chan, ${ }^{1,2}$ Justin C Y Wu, ${ }^{1,2}$ Joseph J Y Sung, ${ }^{1,2}$ Siew C Ng ${ }^{1,2}$
}

- Additional material is published online only. To view please visit the journal online (http://dx.doi.org/10.1136/ thoraxjnl-2015-207811)

For numbered affiliations see end of article.

\section{Correspondence to} Dr Siew C Ng, Department of Medicine and Therapeutics, 30-32 Ngan Shing Street, Prince of Wales Hospital, The Chinese University of Hong Kong, 9/F Lui Che Woo Clinical Sciences Building, Shatin, Hong Kong; siewchienng@cuhk.edu. hk

SHW and QG contributed equally.

Received 7 September 2015 Revised 7 November 2015 Accepted 17 November 2015 Published Online First 11 December 2015

\section{ABSTRACT}

Objective Interferon $\gamma$ release assay (IGRA) is commonly used to diagnose latent TB infection (LTBI). Immunosuppressive therapy may affect its performance but data are conflicting. We aimed to determine the effect of immunosuppressive therapy on the performance of IGRA in patients with autoimmune diseases.

Methods We searched PubMed, MEDLINE, EMBASE and the Cochrane Library up to December 2014. We included studies that reported the IGRA results in patients with autoimmune disease with or without immunosuppressive therapy. The pooled effect of immunosuppressive therapy on IGRA was estimated using a Peto fixed-effects model.

Results We included 17 studies with 3197 participants in the meta-analysis. Among the subjects, $71.5 \%$ were taking immunosuppressive therapy and $56.7 \%$ had received Bacillus Calmette-Guérin vaccination. Compared with patients not on immunosuppressants, patients receiving immunosuppressive therapy were less likely to have a positive IGRA result (OR $0.66,95 \% \mathrm{Cl} 0.53$ to $0.83, I^{2}=23 \%$ ), especially patients receiving anti-tumour necrosis factor (anti-TNF) treatment (OR 0.50, 95\% Cl 0.29 to 0.88). The use of immunosuppressive therapy was also associated with a lower rate of positive tuberculin skin test result (OR $0.51,95 \% \mathrm{Cl} 0.42$ to 0.61).

Conclusions Our meta-analysis showed that IGRA results are negatively affected by immunosuppressive therapy. IGRA alone may not be sufficiently sensitive to diagnose LTBI in patients on immunosuppressive therapy. Patients should preferably be screened for LTBI before initiation of immunosuppressive therapy, especially before anti-TNF therapy.

\section{INTRODUCTION}

TB is a major infectious disease. It was estimated that one-third of the world's population had latent TB infection (LTBI), ${ }^{1}$ of which $5-10 \%$ would develop active TB disease if not being treated. Identifying LTBI is therefore important to control the disease globally. Recently, interferon $\gamma$ release assay (IGRA) has provided an alternative method to tuberculin skin test (TST) in diagnosing LTBI. As IGRA measures interferon $\gamma$ release by $\mathrm{T}$ cells after stimulation with specific TB antigens, it does not cross react with Bacillus Calmette-Guérin (BCG)

\section{Key messages}

What is the key question?

- What is the performance of interferon $\gamma$ release assay (IGRA) in diagnosing latent TB infection (LTBI) in patients on immunosuppressive therapy?

What is the bottom line?

- Screening and treating for LTBI can reduce the rate of TB reactivation and help control the disease globally; however, there are conflicting data on the performance of IGRA in immunocompromised individuals.

\section{Why read on?}

- This meta-analysis shows that IGRA results are negatively affected by immunosuppressive therapy, thus IGRA alone may not be sufficient to diagnose LTBI in patients on immunosuppressive therapy.

and is free from false-positive results in vaccinated individuals. ${ }^{2}$ It has been shown to have a superior sensitivity and specificity than TST in the general population. $^{3} \quad$ The commercially available QuantiFERON-TB Gold In-Tube test (QFT) and T-SPOT.TB test (T-SPOT) have been approved for all situations in which TST is indicated. ${ }^{4}$

Despite its performance in otherwise healthy individuals, there are limited data on the performance of IGRA in patients who are immunocompromised. This clinical uncertainty is recognised by WHO and the US Centers for Disease Control and Prevention (CDC). ${ }^{4}$ Currently, the National Institute for Health and Care Excellence (NICE) recommends either an IGRA alone or an IGRA with a concurrent TST in diagnosing LTBI in people who are immunosuppressed..$^{5}$ Immunosuppressive therapy has been increasingly used for a wide range of autoimmune disorders, including rheumatoid arthritis (RA), systemic lupus erythematosus (SLE), inflammatory bowel diseases (IBD) that collectively affect 5-9\% of the western population. ${ }^{6}$ Many of these patients are receiving corticosteroids, immunosuppressive drugs or monoclonal antibodies such as anti-tumour necrosis factor (anti-TNF) agents. These medications 
are associated with a heightened risk of infection, including reactivation of LTBI and other opportunistic infections. ${ }^{7}$ Testing for LTBI has become mandatory before commencing potent immunosuppressive therapy such as anti-TNF in these patients.

Although a number of studies have assessed the performance of IGRA in patients with autoimmune diseases, uncertainty remains regarding the effect of immunosuppressive therapy on IGRA. Many immunosuppressive agents are potent inhibitors of $\mathrm{T}$ cells and may impair the interferon- $\gamma$ response. ${ }^{8}$ Several studies have reported lower positive or higher indeterminate rates among patients receiving immunosuppressive therapy, although considerable variability existed between studies. Over the next decade, the number of immunosuppressive and biologic agents will continue to expand. We will be caring for an ever aging population with autoimmune diseases and other complex morbidities; therefore the accurate diagnosis of LTBI has become even more important. In this systematic review and meta-analysis, we investigated the effect of immunosuppressive therapy on IGRA in patients with autoimmune diseases.

\section{METHODS}

\section{Data sources and searches}

This study was reported according to the Preferred Reporting Items for Systematic Reviews and Meta-Analyses (PRISMA) guidelines. ${ }^{9}$ An electronic literature search was conducted of articles using the following keywords alone and in combination: 'interferon gamma release assay', 'interferon gamma assay', 'IGRA'，'QuantiFERON', 'T-SPOT.TB', 'tuberculosis', 'autoimmune diseases', 'immune mediated inflammatory diseases', 'inflammatory diseases', 'inflammatory bowel diseases', 'Crohn's disease', 'ulcerative colitis', 'rheumatic diseases', 'rheumatological diseases', 'connective tissue diseases', 'psoriasis', 'psoriatic arthritis', 'rheumatoid arthritis', 'ankylosing spondylitis', 'spondyloarthritis', 'systemic lupus erythematosus' and 'lupus' to identify clinical studies in full publications from six computerised databases: PubMed (1966 to Dec 2014), MEDLINE (1948 to Dec 2014), EMBASE (1974 to Dec 2014), and six databases within the Cochrane Library (1991 to Dec 2014). Only publications in English were included. After removal of duplicate references, initial screening of article titles and abstracts was undertaken by two independent members (QYG and $\mathrm{SHW}$ ). This process removed articles that were not relevant to our study, including editorials, case reports and therapeutic approach articles. Potentially relevant articles were obtained in full text and reviewed independently. Predefined criteria were used to determine eligibility for inclusion. Disagreement at any stage between the two reviewers was resolved by consensus; if consensus could not be reached, a third reviewer $(\mathrm{SCN})$ was consulted for a final decision. We obtained copies of all articles identified as being of potential importance.

\section{Study selection}

Clinical studies were eligible for this meta-analysis if they met the following criteria: (1) clinical studies that assessed the performance of an IGRA in autoimmune diseases; (2) original counts of the results were provided or could be calculated for individuals with and without immunosuppressive therapy. Studies were excluded if they: (1) were not written in English; (2) evaluated a non-commercial, in-house or old generation IGRA; (3) reported insufficient data on IGRA results or had an inappropriate study design that did not assess the performance of an IGRA; (4) were review articles or commentaries. Moreover, if a study provided results for both QFT and T-SPOT, the test with a lower indeterminate rate was used in the combined analysis.

\section{Data extraction and quality assessment}

Data were extracted and assessed for eligibility by two independent reviewers. Extracted data included the primary author, year of publication, country of origin, study design and setting, study size, BCG vaccination rate, proportion of patients on immunosuppressive therapy, disease type, therapeutic medication, methods of IGRA, and IGRA results (positive, negative or indeterminate) with and without immunosuppressive therapy. If TST results were available, the counts of the results were also recorded. As the studies were conducted in different countries with different $\mathrm{TB}$ incidence and BCG vaccination rates, we accepted the definition of a positive TST result used by individual studies.

The main outcome measure was the effect of immunosuppressive therapy on the positive rate of IGRA in patients with autoimmune disease. Secondary outcomes included its effect on the indeterminate rate of IGRA and the positive rate of TST. Subgroup analyses were performed for different methods of IGRA, different medication or disease types.

The quality of included studies was evaluated by using a modified version of QUADAS quality assessment tool which is recommended in systematic reviews of diagnostic accuracy studies. ${ }^{10}$ Given the lack of a reference gold standard in the diagnosis of LTBI, modification of QUADAS was warranted. Each QUADAS item was scored as 'yes', 'no' or 'unclear.' Two reviewers (QYG and SHW) independently reviewed all QUADAS items for each included study with disagreements being resolved by consensus.

\section{Data synthesis and analysis}

The results from included studies were analysed using Review Manager V.5.1 (Nordic Cochrane Centre, Denmark). OR with 95\% CI was used to evaluate the test results among patients with autoimmune disease with or without immunosuppressive therapy. The null hypothesis was rejected at a statistical significance level of $\mathrm{p}<0.05$. Weighted summaries were determined using meta-analysis models if a given result was reported by four or more studies. Tests for heterogeneity were performed for each meta-analysis using Cochrane's $\mathrm{Q}$ test and $\mathrm{I}^{2}$ statistic $\left(\mathrm{I}^{2}<25 \%\right.$ or $>50 \%$ reflects small or large inconsistency respectively). If the heterogeneity test was not significant $(p>0.1)$, the Peto fixed-effects model was used because positive events were not particularly common in some studies; otherwise the DerSimonian and Laird random effects model would be performed.

\section{RESULTS}

\section{Description of the included studies}

The initial search identified 372 abstracts (figure 1). The majority of abstracts were excluded as they were not relevant to the search topic. A total of 83 English language abstracts which involved human subjects were retrieved. Following exclusion, 17 studies comprising 3197 patients published between 2008 and 2014 were included in the final analysis. ${ }^{11-27}$ The study characteristics are shown in table 1.

Most of the studies were conducted in Europe, apart from one conducted in Hong Kong ${ }^{26}$ and two studies conducted within the Asian border of Turkey. ${ }^{17} 27$ The mean age of the subjects was $44.9 \pm 4.7$ years. There was a fair gender distribution $(55.6 \%$ female), except in two SLE studies which included predominantly female participants. ${ }^{12}{ }^{27}$ The number of subjects 


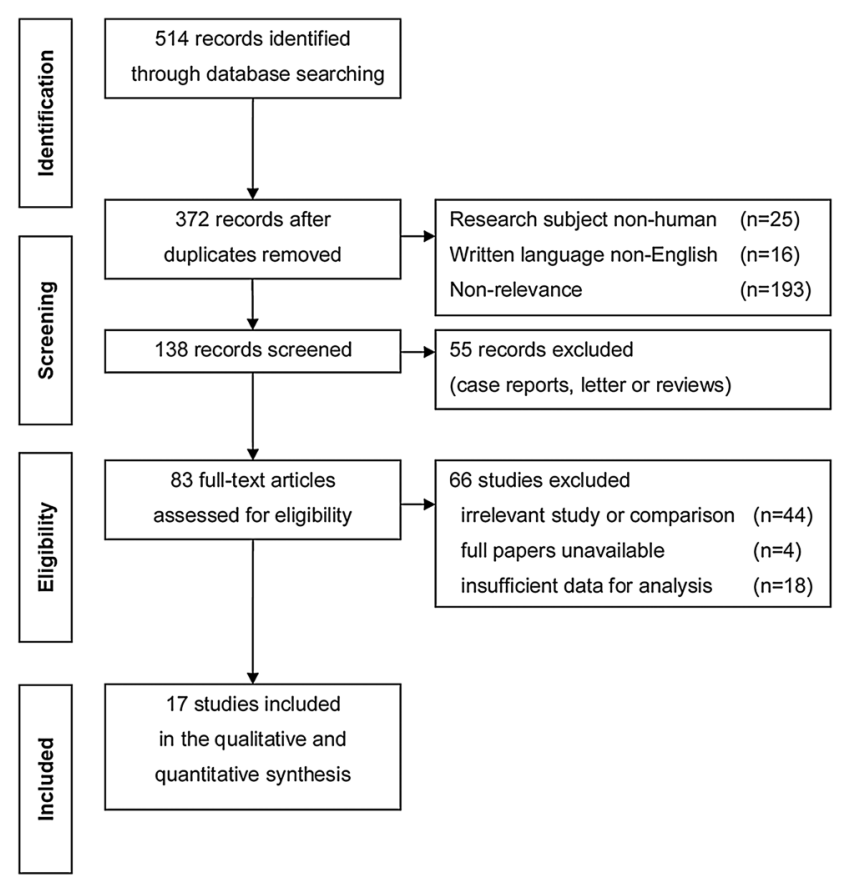

Figure 1 Summary of database search and paper selection.

in each study ranged from 50 to 563 . The average BCG vaccination rate was $56.7 \%$ with a range from $1.1 \%$ in an Italian study $^{11}$ to $100 \%$ in an Austrian study. ${ }^{23}$ The mean percentage of subjects on immunosuppressive therapy was $71.5 \%$, ranging from $43.0 \%$ to $88.7 \%$ (table 2). ${ }^{18} 20$ The majority of the studies evaluated QFT except for three studies which tested T-SPOT $^{12} 16{ }^{19}$; three other studies evaluated QFT and T-SPOT. $^{13} 2021$ The indeterminate rates of IGRA ranged from $1.1 \%{ }^{11}$ to $17.6 \% .^{25}$ TST was performed in all of the studies. The mean concordance rate between TST and IGRA was $77.1 \%$, ranging from $53.3 \%$ to $89.2 \% .{ }^{17}{ }^{18}$ All studies were published as full papers.
Study quality

The QUADAS assessment tool was used to assess the quality of the studies. Overall, most studies satisfied the modified QUADAS items for quality analysis (see online supplementary table S1). However, we observed a high degree of uncertainty for QUADAS items 2 and 4, as many studies did not describe the selection criteria in details and did not mention if IGRA was performed prior to TST. Four of the 17 included papers did not report the indeterminate test results. ${ }^{17-19} 24$

\section{Effect of immunosuppressive therapy on IGRA in autoimmune diseases}

The pooled estimate of 3197 individuals with autoimmune diseases showed that patients on immunosuppressive therapy were less likely to have a positive IGRA result compared with those not receiving immunosuppressive therapy (OR 0.66, 95\% CI 0.53 to 0.83 ). There was no significant heterogeneity of effects between studies. The plots are shown in figure 2 and online supplementary figure S1. This suggested immunosuppressive therapy may negatively affect the IGRA results. Subgroup analyses showed a significant negative impact on the QFT results (OR $0.65,95 \%$ CI 0.50 to 0.84 ) (figure 2). ${ }^{11} 13-15171820-27$ A consistent trend was also observed for T-SPOT; though the pooled estimate from the six studies did not reach statistical significance (OR 0.81, 95\% CI 0.59 to 1.10) (figure 2). ${ }^{12} 13 \quad 16{ }^{19-21}$ Nine studies assessed the effect of immunosuppressive therapy on the

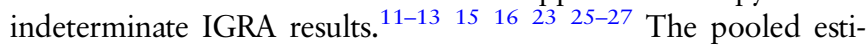
mate showed no significant association between immunosuppressive therapy and the rate of indeterminate results in IGRA (OR $1.10,95 \%$ CI 0.75 to 1.61 ) (see online supplementary figure S2).

\section{Effects of different types of immunosuppressive therapy}

We further evaluated the effects of different immunosuppressive therapies on the IGRA results. Commonly used therapeutic regimens in autoimmune diseases included steroids, oral immunosuppressants and anti-TNF therapy. We identified 11 studies that provided IGRA results in patients taking steroids. ${ }^{12-16}$

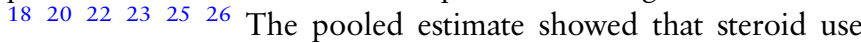

Table 1 Description of the included studies

\begin{tabular}{|c|c|c|c|c|c|c|c|c|c|c|}
\hline First author & Country & Year & $\begin{array}{l}\text { Subject } \\
\text { number }\end{array}$ & $\begin{array}{l}\text { Mean/median } \\
\text { age (years) }\end{array}$ & $\begin{array}{l}\text { Male patients } \\
(\%)\end{array}$ & $\begin{array}{l}\text { BCG rate } \\
(\%)\end{array}$ & $\begin{array}{l}\text { TST cut-off } \\
(\mathrm{mm})\end{array}$ & $\begin{array}{l}\text { Patients on IST } \\
(\%)\end{array}$ & $\begin{array}{l}\text { IGRA } \\
\text { method }\end{array}$ & $\begin{array}{l}\text { ID rate of } \\
\text { IGRA (\%) }\end{array}$ \\
\hline Andrisani & Italy & 2013 & 92 & 39.6 & 50 & 1.1 & $5 / 10$ & 76 & QFT & 1.1 \\
\hline Arenas Miras & Spain & 2014 & 92 & 42.7 & 7.6 & 2.2 & $5 / 10$ & 64.1 & T-SPOT & 4.3 \\
\hline Arias-Guillén & Spain & 2014 & 205 & 42.3 & 50.2 & 89.8 & 5 & 83 & QFT T-SPOT & $2.4^{*}$ \\
\hline Bartalesi & Italy & 2009 & 398 & 54.0 & 34.9 & 4.1 & $5 / 10$ & 78 & QFT & 1.2 \\
\hline Casas & Spain & 2011 & 214 & 48.5 & 49.7 & 23.6 & 5 & 76.2 & QFT & 5.6 \\
\hline Costantino & France & 2013 & 563 & 51.0 & 43 & 78 & 5 & 83.3 & T-SPOT & 15.6 \\
\hline Hanta & Turkey & 2012 & 90 & 40.9 & 48.9 & 92.2 & 5 & 47.8 & QFT & $\mathrm{N} / \mathrm{A}$ \\
\hline Kwakernaak & Netherlands & 2011 & 56 & 50.3 & 53.6 & 5 & 5 & 64.3 & QFT & $\mathrm{N} / \mathrm{A}$ \\
\hline Laffitte & Switzerland & 2009 & 50 & 48.0 & 70 & 90 & $5 / 10$ & 68 & T-SPOT & $\mathrm{N} / \mathrm{A}$ \\
\hline Mariette & France & 2012 & 392 & 45.0 & 41.3 & 65.7 & 5 & 59.7 & QFT T-SPOT & $2.8^{*}$ \\
\hline Martyn-Simmons & UK & 2013 & 70 & 47.0 & 58.6 & 64.3 & $5 / 15$ & 43 & QFT T-SPOT & $4.3^{*}$ \\
\hline Matulis & UK & 2008 & 142 & 47.9 & 50 & 83 & 5 & 89 & QFT & 5.6 \\
\hline Papay & Austria & 2010 & 208 & 36.6 & 48.6 & 100 & $5 / 10$ & 71.6 & QFT & 7.7 \\
\hline Schoepfer & Switzerland & 2008 & 168 & 41.0 & 49.4 & 70.2 & $5 / 15$ & 81 & QFT & $\mathrm{N} / \mathrm{A}$ \\
\hline Scrivo & Italy & 2012 & 119 & 47.0 & 31.1 & 5.9 & 5 & 80.7 & QFT & 17.6 \\
\hline Wong & Hong Kong & 2014 & 265 & 43.1 & 59.7 & 73.1 & 5 & 46.6 & QFT & 1.5 \\
\hline Yilmaz & Turkey & 2012 & 78 & 38.0 & 9 & 97.4 & 5 & 50 & QFT & 2.6 \\
\hline
\end{tabular}

${ }^{*}$ Study that assessed both QFT and T-SPOT. The lower indeterminate rate is presented here.

BCG, Bacillus Calmette-Guérin; ID rate, indeterminate rate; IGRA, interferon $\gamma$ release assay; IST, immunosuppressive therapy; N/A, not available; QFT, QuantiFERON-TB Gold In-Tube test; TST, tuberculin skin test. 
Table 2 Details of immunosuppressive therapy in the included studies

\begin{tabular}{|c|c|c|c|c|}
\hline First author & Drug & Percentage & Dose & Remarks \\
\hline Andrisani & $\begin{array}{l}\text { Azathioprine } \\
\text { Methotrexate } \\
\text { Steroid }\end{array}$ & $\begin{array}{l}41.3 \\
2.1 \\
32.6\end{array}$ & $\begin{array}{l}2.5 \mathrm{mg} / \mathrm{kg} / \text { day }>3 \text { months } \\
10-15 \mathrm{mg} / \text { week }>3 \text { months } \\
\text { Prednisolone }>20 \mathrm{mg} / \text { day for }>2 \text { weeks }\end{array}$ & \\
\hline Arenas Miras & $\begin{array}{l}\text { Prednisolone } \\
\text { Mycophenolate } \\
\text { Methotrexate }\end{array}$ & $\begin{array}{l}19.5 \\
\text { N/A } \\
\text { N/A }\end{array}$ & $\begin{array}{l}>7.5 \mathrm{mg} \\
243.1 \mathrm{mg} \text { (mean) } \\
1.22 \mathrm{mg} \text { (mean) }\end{array}$ & \\
\hline Arias-Guillén & $\begin{array}{l}\text { Immunosuppressant } \\
\text { Steroid } \\
\text { Anti-TNF }\end{array}$ & $\begin{array}{l}31.2 \\
13.2 \\
15.6\end{array}$ & $\begin{array}{l}\text { Used within last } 3 \text { months } \\
\text { Used within last } 2 \text { weeks } \\
\text { Used within last } 12 \text { weeks }\end{array}$ & $\begin{array}{l}\text { Azathioprine, 6-mercaptopurine, methotrexate } \\
\text { Infliximab or adalimumab }\end{array}$ \\
\hline Bartalesi & $\begin{array}{l}\text { DMARDs } \\
\text { Steroid } \\
\text { Anti-TNF }\end{array}$ & $\begin{array}{l}61.6 \\
36.6 \\
24.2\end{array}$ & $\begin{array}{l}\text { N/A } \\
>4 \text { weeks } \\
\text { N/A }\end{array}$ & $\begin{array}{l}\text { Methotrexate, azathioprine, cyclosporine, leflunomide, } \\
\text { cyclophosphamide, hydroxychloroquine } \\
\text { Infliximab, etanercept, adalimumab }\end{array}$ \\
\hline Casas & $\begin{array}{l}\text { Methotrexate } \\
\text { Leflunomide } \\
\text { Cyclosporin A } \\
\text { Others } \\
\text { Steroid }\end{array}$ & $\begin{array}{l}42.5 \\
16.8 \\
10.3 \\
6.1 \\
42.5\end{array}$ & $\begin{array}{l}>4 \text { weeks } \\
>4 \text { weeks } \\
>4 \text { weeks } \\
>4 \text { weeks } \\
>4 \text { weeks }\end{array}$ & Azathioprine, efalizumab \\
\hline Costantino & $\begin{array}{l}\text { DMARDs } \\
\text { Steroid } \\
\text { Anti-TNF }\end{array}$ & $\begin{array}{l}49.2 \\
45.1 \\
16.7\end{array}$ & $\begin{array}{l}\mathrm{N} / \mathrm{A} \\
10 \mathrm{mg} / \text { day } \\
\mathrm{N} / \mathrm{A}\end{array}$ & Methotrexate, leflunomide, others \\
\hline Hanta & Immunosuppressant & $\mathrm{N} / \mathrm{A}$ & $\mathrm{N} / \mathrm{A}$ & \\
\hline Kwakernaak & $\begin{array}{l}\text { Methotrexate } \\
\text { Leflunomide } \\
\text { Azathioprine } \\
\text { Steroid }\end{array}$ & $\begin{array}{l}48.2 \\
5.4 \\
1.8 \\
5\end{array}$ & $\begin{array}{l}19 \mathrm{mg} \text { (mean) } \\
20 \mathrm{mg} \text { (mean) } \\
150 \mathrm{mg} \text { (mean) } \\
6 \mathrm{mg} \text { (mean) }\end{array}$ & These $5 \%$ of patients received only steroid \\
\hline Laffitte & Immunosuppressant & 68 & N/A & Methotrexate, cyclosporine, efalizumab \\
\hline Mariette & $\begin{array}{l}\text { Immunosuppressant } \\
\text { Steroid }\end{array}$ & $\begin{array}{l}50.5 \\
59.7\end{array}$ & $\begin{array}{l}N / A \\
N / A\end{array}$ & \\
\hline Martyn-Simmons & $\begin{array}{l}\text { Cyclosporin } \\
\text { Methotrexate } \\
\text { Fumaric acid ester } \\
\text { Prednisolone } \\
\text { Combinational } \\
\text { Anti-TNF }\end{array}$ & $\begin{array}{l}17.1 \\
15.7 \\
2.9 \\
2.9 \\
2.9 \\
5.7\end{array}$ & $\begin{array}{l}\text { N/A } \\
\text { N/A } \\
\text { N/A } \\
\text { N/A } \\
\text { N/A } \\
\text { N/A }\end{array}$ & \\
\hline Matulis & $\begin{array}{l}\text { Steroid } \\
\text { Anti-TNF }\end{array}$ & $\begin{array}{l}40.1 \\
59.2\end{array}$ & $\begin{array}{l}\text { N/A } \\
\text { N/A }\end{array}$ & $\begin{array}{l}\text { Methotrexate, azathioprine, cyclosporine, } \\
\text { leflunomide, cyclophosphamide, hydroxychloroquine, } \\
\text { sulfasalazine, mycophenolate mofetil, sirolimus } \\
\text { Infliximab, etanercept, adalimumab }\end{array}$ \\
\hline Papay & $\begin{array}{l}\text { Immunosuppressant } \\
\text { Steroid } \\
\text { Anti-TNF }\end{array}$ & 47.1 & $\begin{array}{l}\text { Any dose }>3 \text { months } \\
\text { Any dose }>2 \text { weeks } \\
\text { Any dose within last } 12 \text { weeks }\end{array}$ & Thiopurines, methotrexate \\
\hline Schoepfer & $\begin{array}{l}\text { Immunosuppressant } \\
\text { Steroid } \\
\text { Infliximab }\end{array}$ & 14.9 & $\begin{array}{l}58 \% \text { azathioprine }>2 \mathrm{mg} / \mathrm{kg}, \\
18 \% \text {-mercaptopurine }>1 \mathrm{mg} / \mathrm{kg} \text {, or } \\
24 \% \text { methotrexate }>15 \mathrm{mg} / \mathrm{week} \\
69 \% \text { low dose }(<20 \mathrm{mg} \text { daily) } \\
29 \% \text { moderate dose ( } 20-40 \mathrm{mg} \text { daily) } \\
2 \% \text { high dose ( } 40 \mathrm{mg} \text { daily) } \\
\text { N/A }\end{array}$ & \\
\hline Scrivo & Steroid & 70.6 & $\begin{array}{l}\text { Methotrexate (range } 0-25 \mathrm{mg} \text { ), } \\
\text { leflunomide (range } 0-20 \mathrm{mg} \text {, } \\
\text { cyclosporin (range } 0-250 \mathrm{mg} \text { ), } \\
\text { sulfasalazine (range } 0-3000 \mathrm{mg} \text { ), } \\
\text { azathioprine (range } 0-100 \mathrm{mg} \text {, } \\
\text { hydroxychloroquine (range } 0-400 \mathrm{mg} \text { ) } \\
\text { Prednisone equivalent range } 0-50 \mathrm{mg}\end{array}$ & \\
\hline Wong & $\begin{array}{l}\text { Azathioprine } \\
\text { 6-mercaptopurine } \\
\text { Methotrexate } \\
\text { Steroid }\end{array}$ & $\begin{array}{l}35.1 \\
4.9 \\
4.5 \\
4.1\end{array}$ & $\begin{array}{l}\text { Any dose } \\
\text { Any dose } \\
\text { Any dose } \\
\text { Prednisone }>15 \mathrm{mg} / \text { day for }>1 \text { month }\end{array}$ & \\
\hline Yilmaz & $\begin{array}{l}\text { Hydroxychloroquine } \\
\text { Azathioprine } \\
\text { Mycophenolate mofetil } \\
\text { Cyclophosphamide } \\
\text { Methotrexate } \\
\text { Rituximab } \\
\text { Methylprednisolone }\end{array}$ & $\begin{array}{l}57.5 \\
28.2 \\
7.7 \\
6.4 \\
2.6 \\
1.3 \\
60.3\end{array}$ & $\begin{array}{l}\text { N/A } \\
N / A \\
N / A \\
N / A \\
N / A \\
N / A \\
\text { Methylprednisolone }>10 \mathrm{mg} / \text { day }\end{array}$ & \\
\hline
\end{tabular}

DMARD, disease-modifying antirheumatic drug; TNF, tumour necrosis factor. 


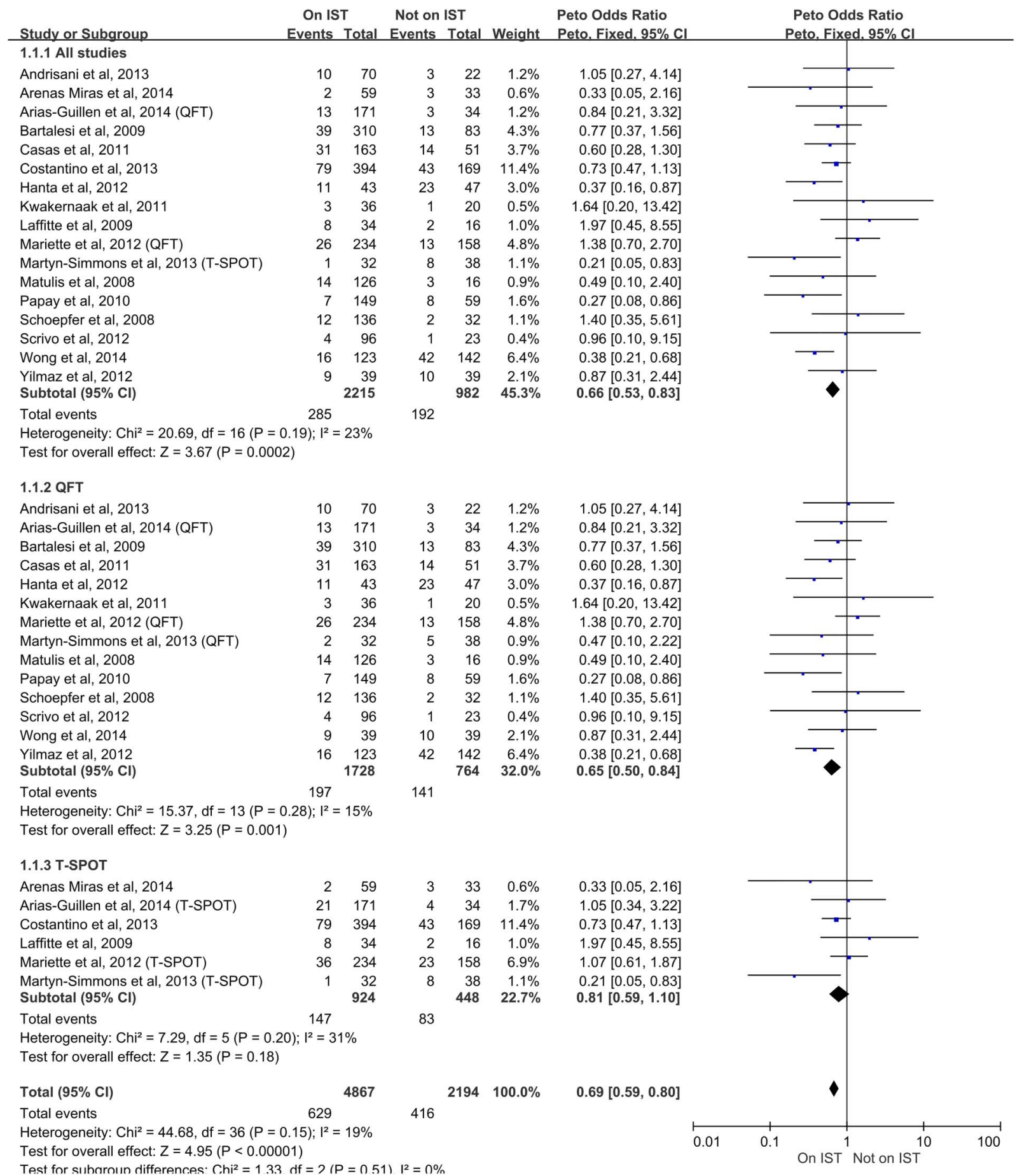

Figure 2 Forest plots of studies comparing positive interferon $\gamma$ release assay (IGRA) results in patients with or without immunosuppressive therapy. The overall analysis (IGRA, top panel) and subgroup analyses (QuantiFERON-TB Gold In-Tube test (QFT), middle panel and T-SPOT, bottom panel) are shown.

was significantly associated with a lower rate of positive IGRA (OR 0.75 , 95\% CI 0.56 to 0.99) (figure 3). Furthermore, data from ten studies on oral immunosuppressants ${ }^{12-}$ $\begin{array}{llllllll}14 & 16 & 18 & 20 & 22 & 23 & 25 & 26\end{array}$ and five studies on anti-TNF agents $^{13} 14222326$ showed a lower proportion of positive IGRA results, with an OR of 0.68 (95\% CI 0.52 to 0.90 ) for oral immunosuppressants and an OR of 0.50 (95\% CI 0.29 to 0.88 ) for anti-TNF therapy (figure 3).

\section{Effect of immunosuppressive therapy on IGRA in different patient groups}

We analysed the effect of immunosuppressive therapy on IGRA in two major groups of diseases: IBD and rheumatological diseases. The IGRA results were retrieved from five studies on

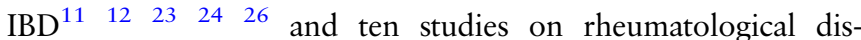
eases. $^{12} 14 \quad 16-1921 \quad 22 \quad 25 \quad 27$ We observed a consistent negative impact of immunosuppressive therapy on the IGRA results in 


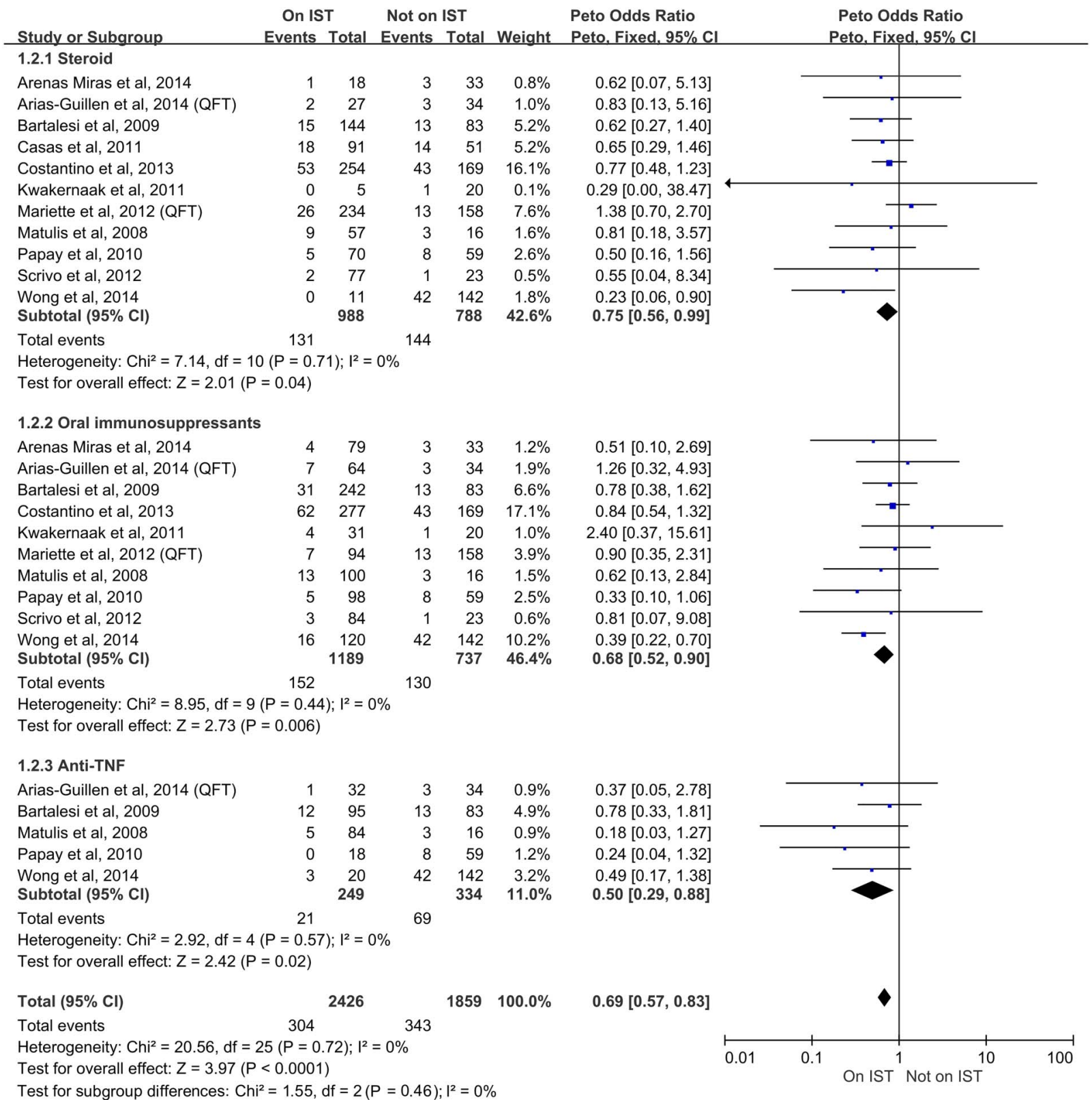

Figure 3 Forest plots of studies comparing positive interferon $\gamma$ release assay (IGRA) results in patients with or without different kinds of immunosuppressive therapy. The subgroup analyses with steroids (top panel), oral immunosuppressants (middle panel) and anti-tumour necrosis factor (TNF) (bottom panel) are shown.

IBD (OR $0.50,95 \%$ CI 0.32 to 0.77 ) and rheumatological disease (OR $0.67,95 \%$ CI 0.50 to 0.90 ) groups (figure 4).

\section{Effect of immunosuppressive therapy on TST in patients with autoimmune disease}

We analysed the effect of immunosuppressive therapy on TST results in patients with autoimmune diseases. Most of the 16 studies showed lower rates of positive TST in patients taking immunosuppressive therapy, with significant associations observed in seven of the studies. ${ }^{11-25} 27$ The rate of TST positive results were $23.2 \%$ and $39.5 \%$ among individuals with or without immunosuppressive therapy respectively. The pooled estimate showed that immunosuppressive therapy was significantly associated with a lower rate of positive TST (OR 0.51, $95 \%$ CI 0.42 to 0.61 ) with no significant heterogeneity between studies (see online supplementary figure S3).

\section{DISCUSSION}

Screening and treating LTBI is an important strategy to control the global spread of TB. There remains a knowledge gap in our understanding of the effect of immunosuppressive therapy on the performance of IGRA for LTBI screening. ${ }^{28} 29$ To our knowledge, this is the first meta-analysis to assess the effect of immunosuppressive therapy on IGRA in patients with autoimmune disease.

In our meta-analysis, we identified a marked negative impact of immunosuppressive therapy on the IGRA results. In the studies, $71.5 \%$ of enrolled subjects were taking immunosuppressive therapy. This represents a common clinical practice nowadays. We found that the results of IGRA were strongly influenced by immunosuppressive therapy comprising steroids, oral immunosuppressants and biological therapy. This effect appeared to be more important in the QFT than the T-SPOT test with a lower Peto OR, although there were fewer studies 


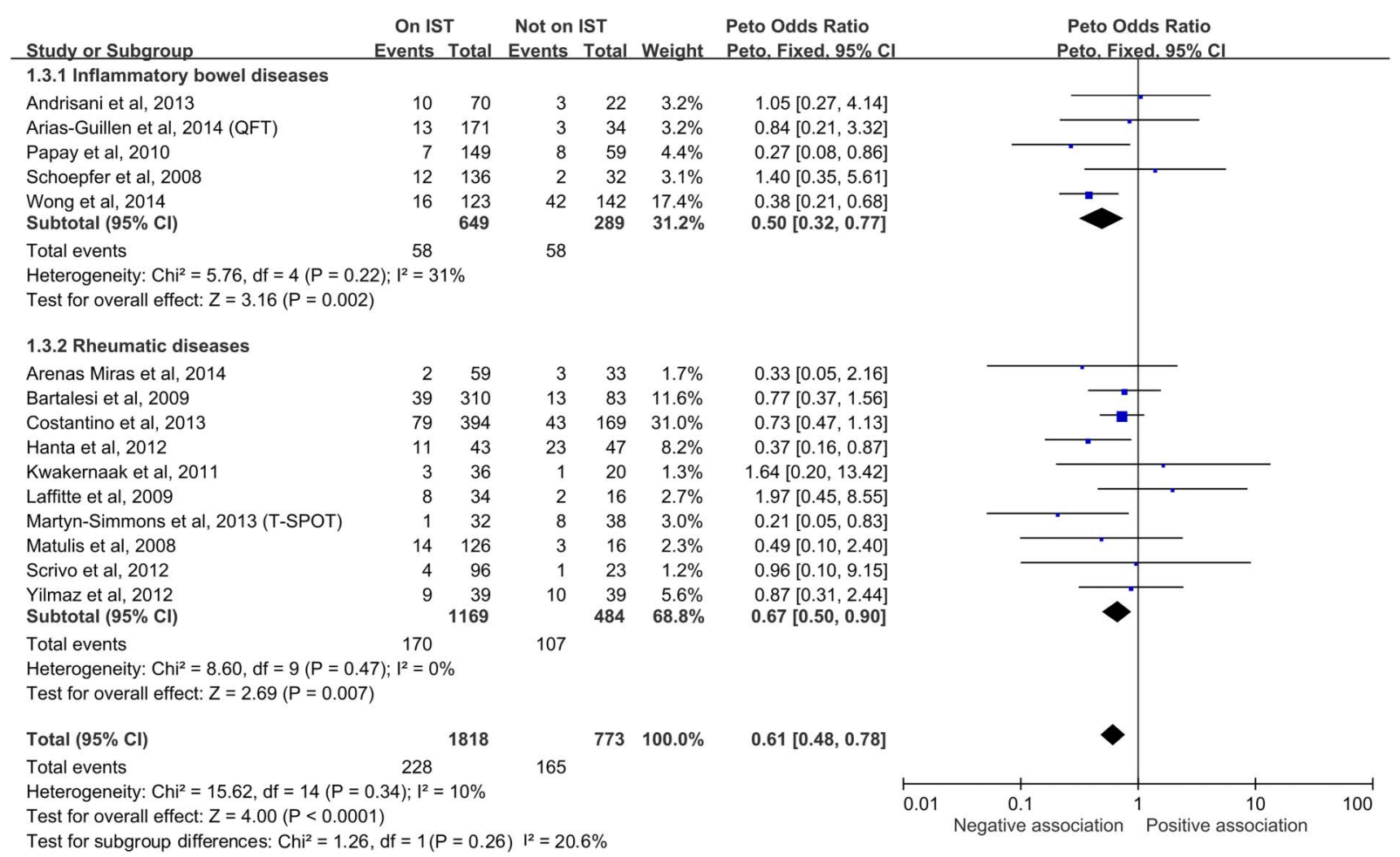

Figure 4 Forest plots of studies comparing positive interferon $\gamma$ release assay (IGRA) results in patients with different groups of disease. The subgroup analyses in patients with inflammatory bowel diseases (top panel) and rheumatic diseases (bottom panel) are shown.

that assessed T-SPOT resulting in smaller statistical power. Although both methods measure interferon $\gamma$ responses to TB-specific antigens (ESAT-6 and CFP-10) over a 16-24 h incubation period, some technical steps are different between the assays. Some studies reported a higher sensitivity with less indeterminate results with the T-SPOT test than the QFT method, ${ }^{30} 31$ and it has been demonstrated that the use of a standardised number of washed peripheral blood mononuclear cells in the T-SPOT assay may contribute to its greater sensitivity. However, the measurement of interferon $\gamma$ in the supernatant of whole blood in the QFT method would adversely affect results in patients with low T-cell counts, which may occur with immunosuppressive therapy. ${ }^{32}$ Our study suggests a possible advantage of the T-SPOT method over the QFT method, ${ }^{2}$ though more studies are required to make a fair comparison between the two tests.

The significant negative impact of anti-TNF therapy on the IGRA result is noteworthy. In clinical practice, it is recommended that patients be screened for LTBI before initiating anti-TNF therapy. ${ }^{5}$ This study provides support for this recommendation, as potent immunosuppressive therapy can undermine the IGRA result significantly (Peto $\mathrm{OR}=0.50$ ). This is likely due to the suppression of interferon $\gamma$ and stimulation of immune cell apoptosis. ${ }^{33}$ There is a concern that IGRA may not be sensitive in patients already on anti-TNF.

Furthermore, this negative impact on the IGRA results was also seen with other immunosuppressive agents, including steroids or oral immunosuppressants. This is consistent with some previous studies showing the negative impact of immunosuppressive therapy. ${ }^{35-37}$ Moreover, two other papers suggested that about $7.5-10 \mathrm{mg} /$ day of steroids may have enough suppressive effect on T-cell responsiveness which could negatively affect performance of immunodiagnostic tests for LTBI. ${ }^{38} 39$ Although the results from some studies are conflicting, ${ }^{13} 1820$ our data favour a negative impact on the IGRA results from steroids and oral immunosuppressants with no significant heterogeneity between studies. This is in contrast to several individual studies claiming an absence of effect of IGRA, ${ }^{12-14} 2122$ despite each of them having insufficient power to detect such an effect. Assuming a true effect size with an OR of 0.75 for steroids as estimated in this meta-analysis, up to 1617 samples are required to achieve a power of $80 \%$ at an $\alpha$ error rate of $5 \%$. It is likely that even the largest study, ${ }^{16}$ with a total sample size less than one-third of this estimation, would be inadequate to conclude the steroid effect on IGRA. Combining data from 11 studies with 1776 subjects, our meta-analysis offered a greater power than any of the individual studies to detect a significant effect. Nevertheless, it is noteworthy that the studies used medications at different doses with different routes of administration, and the heterogeneity may not have been captured in the statistical analyses.

Another interesting finding is that although immunosuppressive therapy strongly effects the performance of IGRA, it appears to have no significant correlation with the rates of indeterminate results. This may be explained by patient-related or test-related factors. Low peripheral blood lymphocyte count, low serum albumin and treatment with immunosuppressive therapy were reported as predictors of indeterminate results. ${ }^{40}$ Furthermore, the overall rate of indeterminate results is relatively low, thus affecting the power to detect a significant difference. In this analysis, only two of the nine studies reported an indeterminate rate of above $10 \%,{ }^{16} 25$ and the average indeterminate rate of the remaining seven studies was around 5\%. Despite a lower IGRA positive rate, we did not observe a higher indeterminate rate among patients on immunosuppressive therapy, suggesting that the drugs may have undermined the test to produce more negative but not indeterminate results.

Our study has several limitations. First, despite subgroup analyses of different classes of immunosuppressive therapy, the 
effect of individual therapeutic agents could not be ascertained due to the insufficient raw data. For example, only three studies have provided the raw data for thiopurine or methotrexate ${ }^{18} 2{ }^{26}$; and only four studies on steroids mentioned the dosage used $\left(5-10 \mathrm{mg}\right.$ per day respectively $\left.{ }^{12} 15{ }^{18}{ }^{26}\right)$. Further stratified analyses on these individual immunosuppressants cannot be calculated from the original publications. Second, age may also affect the likelihood of positive or indeterminate IGRA results. However, as the raw data for each individual study with and without immunosuppressive therapy were not available, we were unable to assess the effect of age as a potential confounder in a meta-regression. Nevertheless, given the relatively young age of subjects in the individual studies (range 36.654.0 , table 1), this effect is likely to be limited. Third, as we compared individuals with autoimmune diseases, there could be other possible confounding factors associated with the immunosuppressive therapy. These factors may include the different formulations of medications, disease activity and associated comorbidities. These effects may not be captured in the statistical analyses due to the heterogeneity of study design and limited available data.

In conclusion, this meta-analysis showed a pronounced negative impact of immunosuppressive therapy on the IGRA results. Our findings suggest that IGRA may not be reliable in the diagnosis of LTBI of patients on immunosuppressive therapy, including anti-TNF, steroids and oral immunosuppressants. Patients should preferably be screened for LTBI before initiation of immunosuppressive therapy. These results would be useful to physicians in pulmonology, infectious disease, rheumatology, gastroenterology and dermatology specialties in understanding how reliable IGRA is when tested in patients already on some forms of immunosuppressants.

\section{Author affiliations \\ ${ }^{1}$ Department of Medicine and Therapeutics, The Chinese University of Hong Kong, Shatin, Hong Kong \\ ${ }^{2}$ State Key Laboratory of Digestive Diseases, Institute of Digestive Disease, LKS Institute of Health Science, The Chinese University of Hong Kong, Shatin, Hong Kong \\ ${ }^{3}$ Division of Gastroenterology and Hepatology, Ren-Ji Hospital, Shanghai Jiao-Tong University School of Medicine, Shanghai Institute of Digestive Disease, Shanghai 200240, China \\ ${ }^{4}$ Faculty of Medicine, School of Public Health and Primary Care, Institute of Digestive Disease, The Chinese University of Hong Kong, Shatin, Hong Kong \\ ${ }^{5}$ Department of Anaesthesia and Intensive Care, The Chinese University of Hong Kong, Shatin, Hong Kong}

Contributors SHW, QG and SCN take responsibility for the integrity of the data and the accuracy of the data analysis. All authors approved the final version of the manuscript. Study concept and design: SHW, QG and SCN. Acquisition, analysis, or interpretation of data: SHW, QG, KKFT, WKKW and SCN. Drafting of the manuscript: SHW, QG, L-ST, NL, JJYS and SCN. Critical revision of the manuscript for important intellectual content: all authors. Statistical analysis: SHW, QG, KKFT and WKKW. Study supervision: L-ST, NL, FKLC, JCYW, JJYS and SCN.

Funding SHW is supported by the Croucher Foundation Hong Kong. QG is supported by the National Natural Science Foundation of China (grant \#81302085). The funders had no role in study design, data collection and analysis, decision to publish, or preparation of the manuscript.

Competing interests None declared.

Provenance and peer review Not commissioned; externally peer reviewed.

\section{REFERENCES}

1 Scott C, Kirking HL, Jeffries C, et al. Tuberculosis trends—United States, 2014 MMWR Morb Mortal Wkly Rep 2015;64:265-9.

2 Pai M, Zwerling A, Menzies D. Systematic review: T-cell-based assays for the diagnosis of latent tuberculosis infection: an update. Ann Intern Med 2008;149:177-84.

3 Chang KC, Leung CC. Systematic review of interferon-gamma release assays in tuberculosis: focus on likelihood ratios. Thorax 2010;65:271-6.
4 Centers for Disease Control and Prevention (CDC). Mortality among patients with tuberculosis and associations with HIV status-United States, 1993-2008. MMWR Morb Mortal Wkly Rep 2010;59:1509-13.

5 British Thoracic Society Standards of Care Committee. BTS recommendations for assessing risk and for managing Mycobacterium tuberculosis infection and disease in patients due to start anti-TNF-alpha treatment. Thorax 2005;60:800-5.

6 Cooper GS, Bynum ML, Somers EC. Recent insights in the epidemiology of autoimmune diseases: improved prevalence estimates and understanding of clustering of diseases. J Autoimmun 2009;33:197-207.

7 Keane J, Gershon S, Wise RP, et al. Tuberculosis associated with infliximab, a tumor necrosis factor alpha-neutralizing agent. N Engl J Med 2001;345:1098-104.

8 Sester U, Wilkens $\mathrm{H}$, van Bentum $\mathrm{K}$, et al. Impaired detection of Mycobacterium tuberculosis immunity in patients using high levels of immunosuppressive drugs. Eur Respir J 2009;34:702-10.

9 McLeroy KR, Northridge ME, Balcazar $\mathrm{H}$, et al. Reporting guidelines and the American Journal of Public Health's adoption of preferred reporting items for systematic reviews and meta-analyses. Am J Public Health 2012 102:780-4

10 Whiting P, Rutjes AW, Reitsma JB, et al. The development of QUADAS: a tool for the quality assessment of studies of diagnostic accuracy included in systematic reviews. BMC Med Res Methodol 2003:3:25.

11 Andrisani G, Armuzzi A, Papa A, et al. Comparison of Quantiferon-TB Gold versus tuberculin skin test for tuberculosis screening in inflammatory bowel disease patients. J Gastrointestin Liver Dis 2013;22:21-5.

12 Arenas Miras MdM, Hidalgo-Tenorio C, Jimenez-Gamiz P, et al. Diagnosis of latent tuberculosis in patients with systemic lupus erythematosus: T.SPOT.TB versus tuberculin skin test. Biomed Res Int 2014;2014:291031.

13 Arias-Guillen $\mathrm{M}$, Riestra $\mathrm{S}$, de Francisco $\mathrm{R}$, et al. T-cell profiling and the immunodiagnosis of latent tuberculosis infection in patients with inflammatory bowel disease. Inflamm Bowel Dis 2014;20:329-38.

14 Bartalesi F, Vicidomini S, Goletti D, et al. QuantiFERON-TB Gold and the TST are both useful for latent tuberculosis infection screening in autoimmune diseases. Eur Respir J 2009;33:586-93.

15 Casas S, Andreu A, Juanola X, et al. Diagnosis of tuberculosis infection by tuberculin skin test and a whole-blood interferon- $\gamma$ release assay in patients considered for anti-tumor necrosis factor- $\alpha$ therapy. Diagn Microbiol Infect Dis 2011;71:57-65.

16 Costantino F, de Carvalho Bittencourt M, Rat AC, et al. Screening for latent tuberculosis infection in patients with chronic inflammatory arthritis: discrepancies between tuberculin skin test and interferon- $\gamma$ release assay results. J Rheumatol 2013;40:1986-93.

17 Hanta I, Ozbek S, Kuleci S, et al. Detection of latent tuberculosis infection in rheumatologic diseases before anti-TNFalpha therapy: tuberculin skin test versus IFN- $\gamma$ assay. Rheumatol Int 2012;32:3599-603.

18 Kwakernaak AJ, Houtman PM, Weel JF, et al. A comparison of an interferon-gamma release assay and tuberculin skin test in refractory inflammatory disease patients screened for latent tuberculosis prior to the initiation of a first tumor necrosis factor $\alpha$ inhibitor. Clin Rheumatol 2011;30:505-10.

19 Laffitte $\mathrm{E}$, Janssens JP, Roux-Lombard $\mathrm{P}$, et al. Tuberculosis screening in patients with psoriasis before antitumour necrosis factor therapy: comparison of an interferon-gamma release assay vs. tuberculin skin test. $\mathrm{Br}$ I Dermatol 2009;161:797-800

20 Mariette $X$, Baron G, Tubach $F$, et al. Influence of replacing tuberculin skin test with ex vivo interferon gamma release assays on decision to administer prophylactic antituberculosis antibiotics before anti-TNF therapy. Ann Rheum Dis 2012;71:1783-90.

21 Martyn-Simmons CL, Mee JB, Kirkham BW, et al. Evaluating the use of the interferon- $\gamma$ response to Mycobacterium tuberculosis-specific antigens in patients with psoriasis prior to antitumour necrosis factor-alpha therapy: a prospective head-to-head cross-sectional study. Br J Dermatol 2013;168:1012-18.

22 Matulis G, Juni P, Villiger PM, et al. Detection of latent tuberculosis in immunosuppressed patients with autoimmune diseases: performance of a Mycobacterium tuberculosis antigen-specific interferon gamma assay. Ann Rheum Dis 2008;67:84-90.

23 Papay $P$, Eser $A$, Winkler $S$, et al. Factors impacting the results of interferon- $\gamma$ release assay and tuberculin skin test in routine screening for latent tuberculosis in patients with inflammatory bowel diseases. Inflamm Bowel Dis 2011;17:84-90.

24 Schoepfer AM, Flogerzi B, Fallegger $S$, et al. Comparison of interferon-gamma release assay versus tuberculin skin test for tuberculosis screening in inflammatory bowel disease. Am J Gastroenterol 2008;103:2799-806.

25 Scrivo $R$, Sauzullo I, Mengoni $F$, et al. Serial interferon- $\gamma$ release assays for screening and monitoring of tuberculosis infection during treatment with biologic agents. Clin Rheumatol 2012:31:1567-75.

26 Wong SH, Ip M, Tang W, et al. Performance of interferon-gamma release assay for tuberculosis screening in inflammatory bowel disease patients. Inflamm Bowel Dis 2014;20:2067-72.

27 Yilmaz N, Zehra Aydin S, Inanc N, et al. Comparison of QuantiFERON-TB Gold test and tuberculin skin test for the identification of latent Mycobacterium tuberculosis infection in lupus patients. Lupus 2012;21:491-5. 


\section{Tuberculosis}

28 Mazurek GH, Jereb J, Vernon A, et al. Updated guidelines for using interferon gamma release assays to detect Mycobacterium tuberculosis infection-United States, 2010. MMWR Recomm Rep 2010;59(RR-5):1-25.

29 World Health Organization. Use of interferon-gamma release assays (IGRAs) in tuberculosis control in low- and middle-income settings: expert group meeting report. Geneva, Switzerland, 2010.

30 Arend SM, Thijsen SF, Leyten EM, et al. Comparison of two interferon-gamma assays and tuberculin skin test for tracing tuberculosis contacts. Am J Respir Crit Care Med 2007;175:618-27.

31 Bocchino M, Matarese A, Bellofiore B, et al. Performance of two commercial blood IFN-gamma release assays for the detection of Mycobacterium tuberculosis infection in patient candidates for anti-TNF-alpha treatment. Eur J Clin Microbiol Infect Dis 2008;27:907-13.

32 Dewan PK, Grinsdale J, Kawamura LM. Low sensitivity of a whole-blood interferon-gamma release assay for detection of active tuberculosis. Clin Infect Dis 2007;44:69-73.

33 Harris J, Keane J. How tumour necrosis factor blockers interfere with tuberculosis immunity. Clin Exp Immunol 2010;161:1-9.

34 Hatemi G, Melikoglu M, Ozbakir F, et al. Quantiferon-TB Gold in tube assay for the screening of tuberculosis before and during treatment with tumor necrosis factor alpha antagonists. Arthritis Res Ther 2012;14:R147.
35 Belard E, Semb S, Ruhwald M, et al. Prednisolone treatment affects the performance of the QuantiFERON gold in-tube test and the tuberculin skin test in patients with autoimmune disorders screened for latent tuberculosis infection. Inflamm Bowel Dis 2011;17:2340-9.

36 Soborg B, Ruhwald M, Hetland ML, et al. Comparison of screening procedures for Mycobacterium tuberculosis infection among patients with inflammatory diseases. J Rheumatol 2009;36:1876-84.

37 Shahidi N, Fu YT, Qian H, et al. Performance of interferon-gamma release assays in patients with inflammatory bowel disease: a systematic review and meta-analysis. Inflamm Bowel Dis 2012;18:2034-42.

38 Kleinert $\mathrm{S}$, Kurzai 0 , Elias J, et al. Comparison of two interferon-gamma release assays and tuberculin skin test for detecting latent tuberculosis in patients with immune-mediated inflammatory diseases. Ann Rheum Dis 2010; 69:782-4.

39 Ponce de Leon D, Acevedo-Vasquez E, Alvizuri S, et al. Comparison of an interferon-gamma assay with tuberculin skin testing for detection of tuberculosis (TB) infection in patients with rheumatoid arthritis in a TB-endemic population. J Rheumatol 2008;35:776-81.

40 Papay $\mathrm{P}$, Eser $\mathrm{A}$, Winkler $\mathrm{S}$, et al. Predictors of indeterminate IFN- $\gamma$ release assay in screening for latent TB in inflammatory bowel diseases. Eur J Clin Invest 2011;41:1071-6. 